\title{
Açık Kaynak Kodlu Taşıt Renk Tespit Yazılımı Geliştirilmesi
}

\author{
Burak Ağgül ${ }^{\mathrm{a} 1, *}$, Gökhan Erdemir ${ }^{\mathrm{a} 2}$ \\ a İstanbul Sabahattin Zaim Üniversitesi, Lisansüstü Eğitim Enstitüsü, Bilgisayar Bilimleri ve Mühendisliği Bölümü, İstanbul, Türkiye \\ İstanbul Sabahattin Zaim Üniversitesi Fen Bilimleri Enstitüsü Dergisi (2021) 3 (1): $47-50$ \\ https://doi.org/10.47769/izufbed.880007 \\ (iD) ORCID ${ }_{1}^{1} 0000-0002-9183-1568 ;{ }^{2} 0000-0003-4095-6333$
}

\begin{tabular}{l} 
YAYIN BİLGİSI \\
\hline Yayın geçmişi: \\
Gönderilen tarih: 14 Şubat 2021 \\
Kabul tarihi:03 Mart 2021 \\
\hline Anahtar kelimeler: \\
Araç renk tespiti \\
Renk uzayı \\
Renk bölgesi
\end{tabular}

\begin{abstract}
ÖZET
Günümüz teknolojisinde gelişen bilgisayarlar hayatın her alanında aktif olarak kullanmaktadır. İş, eğitim, sosyal vb. alanlarda işlerimizi kolaylaştırmamıza yardımcı olan bu sistemler geliştikçe işlem yapabilmek ya da problem çözmek daha da kolay hale geldiği anlaşılmaktadır. Bu alanların hemen hemen hepsinin içerisinde yer alan görüntü ya da resim niteliği bulunan dosya veya dosyalar üzerinde ihtiyaca göre bir takım morfolojik işlemler gerçekleştirilebilir. Bu çalışmanın amacı herhangi bir araç görüntüsü alınarak aracın renginin tespit edilmesidir. Tespit edilen renk ihtiyaca göre kullanıldığı alanlar farklılık gösterebilir. Örneğin bir plaka okuma sisteminde araç bilgisi eşleştirmek için renk bulgusu önemli bir faktördür. Buna benzer birçok alanda ihtiyaç duyulan araç renk bilgisi için birçok farklı uygulama alanları ve yöntemleri mevcuttur. Bu tarz uygulama alanlarında kullanılmak üzere karmaşıklığı minimum düzeyde olan bir algoritma tasarlanmıştır. Sistem, python programlama dili kullanılarak tasarlanmıştır. Doğruluk oranı resmin piksel kalitesi ile direkt olarak doğru orantılıdır.
\end{abstract}

\section{Development of Open Source Vehicle Color Detection Software}

\begin{tabular}{l}
\hline ARTICLE INFO \\
\hline Article history: \\
Received: 14 February 2021 \\
Accepted: 03 March 2021 \\
\hline Key words: \\
Vehicle color detection \\
Color space \\
Color zone
\end{tabular}

\begin{abstract}
Computers developed in today's technology are actively used in all areas of life. Business, education, social, etc. It is understood that as these systems, which help us facilitate our work in the fields, it becomes easier to act or solve problems. A number of morphological operations can be performed on the files or files that have image or picture quality in almost all of these areas. The purpose of this study is to determine the color of the vehicle by taking any vehicle image. The areas where the detected color is used may differ depending on the need. Color indication is an important factor in matching vehicle information, for example in a license plate reading system. There are many different application areas and methods for vehicle color information needed in many similar areas. An algorithm with minimal complexity has been designed to be used in such application areas. The system is designed using the python programming language. The accuracy rate is directly proportional to the pixel quality of the picture.
\end{abstract}

\section{Giriş}

$\mathrm{Bu}$ çalı̧̧ma araç görüntüsü üzerinden aracın rengini tespit edilebilmesi için tasarlanmıştır. Temel olarak, bir görüntü üzerinde işlem yapılabilmesi için ilgili görüntünün siyah beyaz ya da gri olması beklenilmektedir. Fakat bu durum probleme ya da çalışmaya bağlı olarak farklılık göstermektedir. Yazılımsal olarak ulaşılan seviyeye donanımsal olarak ulaşılamamış olması problemlerin çözümünde olumsuzluklara sebebiyet vermektedir. Yavaş çalışan sistemler, donma, işleme tepki vermeme vb. gibi sorunları ortaya çıkarmaktadır. Bu nedenle siyah beyaz ya da griye dönüştürülerek yürütülen sistemler tasarlanması tercih edilir. Fakat bu çalışmanın örneği gibi bazı problemlerde en temel adım görüntünün renkli olması ve renkli olarak işleme tabi tutulmasıdır.

Aracın renk bilgisi tespit edilebilmesi için araç görüntüsü üzerinde bazı morfolojik işlemler olarak adlandırılan adımlar 
uygulanmaktadır. Araca ait ön, arka ya da yan tarafindan çekilen görüntü üzerinde belirli bir nokta aralığının kırpılarak alınması, alınan bu görüntü üzerindeki tüm piksellere ait değerlerin toplanması ile renk tahmininde bulunulması amaçlanmıştır.

Araç marka, model, plaka ve renk tanıma gibi işlemlerde derin öğrenme metotları kullanılmaktadır. Öğrenmeye dayalı bu yaklaşımda en çok tercih edilen model evrişimli sinir ağlarıdır (CNN) (Q. Zhang, 2018) (Kwang-Ju Kim, 2018). Karayollarında konuşlu farklı türdeki kameralardan elde edile görüntüler üzerinde çeşitli iyileştirilmeler yapılarak araçların renk tespiti derin öğrenme metotları kullanılarak tespit edilmektedir (Kwang-Ju Kim, 2018) (Q. Zhang, 2018). Diğer algoritmalara göre daha az veri seti ile sonuç üretebilen $\mathrm{CNN}$, araç renk tanıma işlemi için önerilen bir algoritmadır[1]. Farklı renk gruplarının tespit edilebilmesi için ölçekli kapsamlı özellikli füzyon evrişimli sinir ağı (MCFF-CNN) (Huiyuan Fu, 2020) literatürde kullanılan bir başka yaklaşımdır.

Karayollarında seyir halinde bulunan araçların plaka okuma kamera görüntüleri üzerinde çalışan derin öğrenme tabanlı araç marka, model ve renk tespiti eş zamanlı olarak gerçekleştirilmelidir. $\mathrm{Bu}$ yüzden gerçek zamanlı görüntüler üzerinde yüksek doğruluk oranına ile anlık tespit yapılması gerekmektedir (Yusuf Artan, 2019), (Mengjie Yang, 2011). Renk tespitine yönelik çalışmalarda tüm araç bölgesinin kullanılmasının başarıyı arttırdığı gözlenmektedir (Yusuf Artan, 2019), (Mengjie Yang, 2011). Bir başka yaklaşım ise, şablonun vektör eşleştirmesinden esinlenen bir yöntem ve video ön işlem için bir renk normalleştirme operatörü oluşturulduktan sonra HSI renk uzayını ve göreceli hata mesafesi eşleştirme algoritması ile hassas renk tanımlaması gerçekleştirmektir (Mengjie Yang, 2011), (Xiuzhi Li, 2010). Trafikte monoküler kamera ile kaydedilen videoları işleyerek, trafiği herhangi bir yönden geçen araçların tek renkli görüntüsünü alarak renk tespitinde bulunulması kullanılan yaklaşımlardan birisidir (Mengjie Yang, 2011).

\section{Materyal ve Yöntem}

Araca ait rengi tanımanın en temel zorluğu, baskın rengin tespiti için ilgili bölgeyi (ROI) seçmektir. Araç rengi, ROI renginin göreceli konumu ve spektrumdaki plaka rengi ile tanımlanır (Yanmei Dong, 2015). İlk olarak, tespit edilen görüntü, araç görüntüsünü vurgulamak için çok sayıda arka plan bilgisini ortadan kaldırabilen yerel özelliklere dayalı olarak görüntü belirginlik tespiti ile önceden işlenir (Tiantian Wang, 2015). Daha sonra bu alanın genel ağırlıklı renk skalası bulunarak renk tespiti sonlandırılır (Yanmei Dong, 2015), (Brody Huval, 2015), (Feng Wang, 2008).

Aracın rengini, meyvenin, giysinin ya da herhangi bir nesnenin rengini tespit edebilmek için o nesneye ait görüntünün renkli olması gerekmektedir. Bu durumda sistem üzerinde oluşacak olumsuz etkinin en aza indirgenmesi gereklidir. $\mathrm{Bu}$ aşamada görüntünün tamamı ile ilgilenmek yerine görüntü üzerinden belirli bölge veya bölgeler kırpılarak işleme alınacak piksel sayısı düşürülmektedir (Yanmei Dong, 2015), (Brody Huval, 2015). Dikkat edilmesi gereken adım nesnenin renginin doğru tespit edilebilmesi için kırpılacak bölgenin doğru belirlenmesidir.

\subsection{Görüntü İşleme}

Bir görüntü birden fazla piksellerden oluşmaktadır. Bu piksellerin her biri kırmızı, yeşil ve mavi renklerden oluşmaktadır. Her renk için 0 ile 255 aralığında değer almaktadır. $\mathrm{Bu}$ üç rengin karışım yoğunluklarından diğer renkler oluşmaktadır. Görüntü işlemle adımları genellikle probleme göre farklılık göstermektedir.

\subsection{Renk Algılama ve Tanımlama}

Python programlama dili kullanılarak tasarlanan bu sistemde görüntü işleme kütüphanesi OpenCV, görüntüleme kütüphanesi olarak python imaging library kullanılmıştır. Renk tespiti yapılacak araç görüntüleri için uygulanacak ilk adım görüntülerin aynı piksel ölçülerinde olmasıdır. Şekil 1 'de test için kullanılan araç görüntülerinden bir tanesi verilmiştir. Kırpılacak bölge her resim için ortalama aynı bölgeye denk gelecek şekilde bir değer belirlenmiştir.

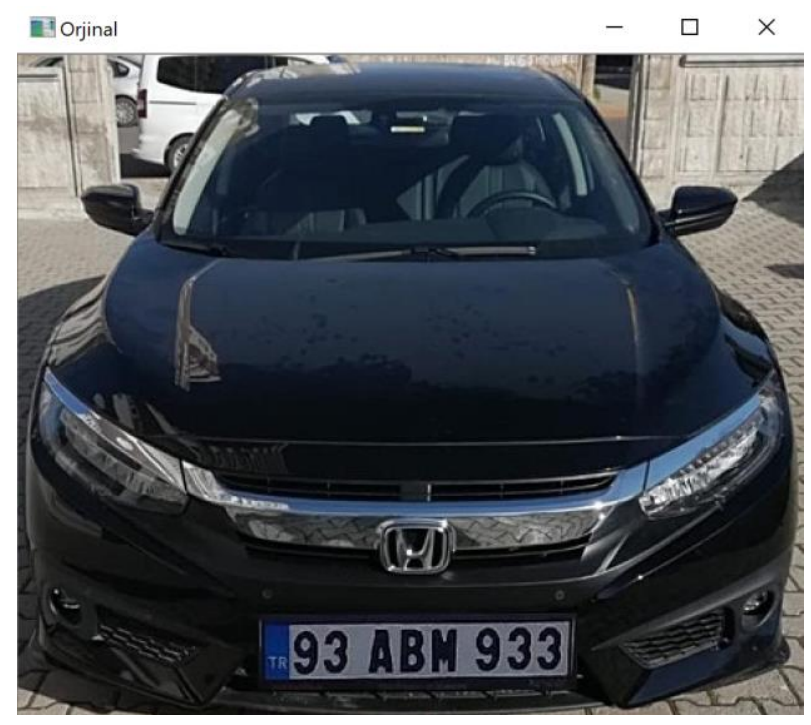

Şekil 1. Örnek araç görüntüsü

$\mathrm{Bu}$ çalışmada test verisi olarak araçlara ait ön ve arka görüntüler kullanılmıştır. Görüntü imread fonksiyonu ile okunmaktadır. Daha sonra resize fonksiyonu sayesinde yeniden ölçeklendirilir. Ölçeklendirilmiş olan örnek araç görüntüsü Şekil 2'de gösterilmiştir.

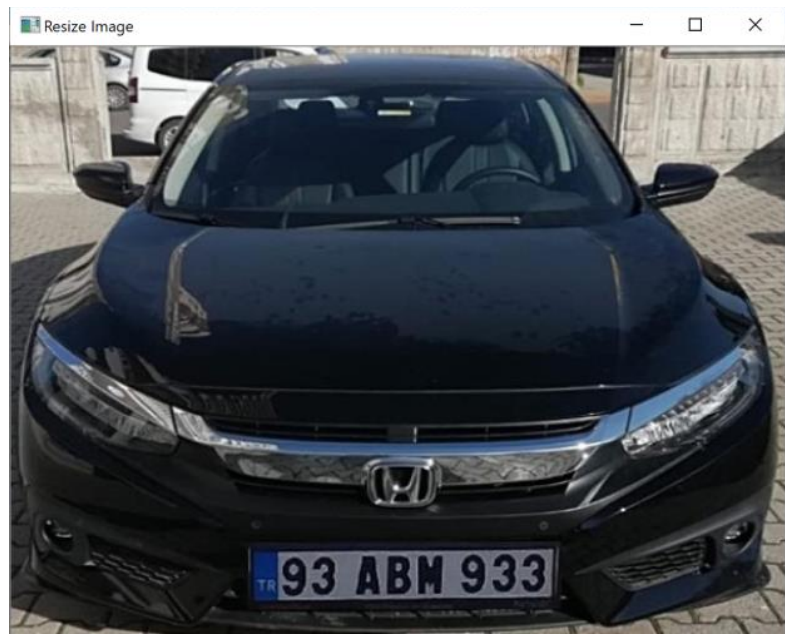

Şekil 2. Ölçeklendirilmiş örnek araç görüntüsü 
Elde edilen yeni görüntü bizim için işleme alınacak yeni görüntüyü temsil etmektedir. Sıradaki adım renk tespitinde kullanılacak bölgenin kırpılması işlemidir. Bu bölgenin tespiti birkaç deneme yapılarak en uygun bölgenin bulunması gerekmektedir. Yapılan denemeler sonucu aracın ön ya da arka tarafından çekilmiş görüntü için yükseklik ve geniş bilgilerine ihtiyaç duyulmaktadır. Bu adım için zaten ihtiyaç duyulan bilgi elimizde mevcuttur. Resize fonksiyonu ile belirlediğimiz değerlerdir. Belirlenen değerler bu çalışma için 600 x 450 piksel ölçüleridir.

Kirpılacak bölge, aracın ön görüntüsü için araca ait kaput bölgesi, arka görüntüsü için araca ait bagaj kapağı bölgesine denk gelecek şekilde ortalama bir değer aralığı belirlenmiştir. Aracın fotoğrafında bulunan ve renk tespitinde olumsuz etki yaratacak diğer renkleri içeren bölgelerden, arındırmak için koordinatlar belirlenir. Bu koordinatlar belirlenirken deneme yapılarak en iyi değer aralığı belirlenmiştir.

Kırpılacak bölge için dört adet değere ihtiyaç duyulmaktadır. Bu değerler x1, x2, y1, y2 ya da sol, üst, sağ, alt şeklinde de tanımlanır. Bu sayede yeni görüntümüzün alanları belirlenmiş olmaktadır. Örnek araç üzerinde belirlenen kesit alanı Şekil 3'de gösterilmiştir.

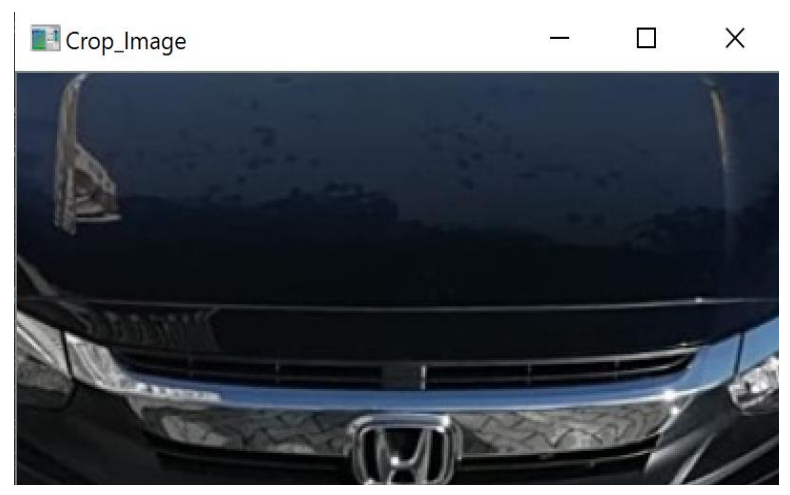

Şekil 3. Örnek araç üzerinde belirlenen kesit alanı

Artık elimizde renk tespitine en uygun bölgelerden birisi olan yeni görüntü oluşturulmuştur. Görsel üzerinde farklı renk bilgileri mevcut olsa da araca ait rengi temsil eden renk bölgesinin daha fazla olduğu insan gözü ile görülmektedir. Bu sayede görsel üzerinde mevcut tüm piksellerin renk değerlerinin toplamı bize ortalama renk bilgisi üzerine bir tahminde bulunmamıza olanak sağlamaktadır.

\section{Bulgular ve Tartışma}

Tasarlanan bu sistem ile 6 farklı renk tespiti yapılmaktadır. Bunlar; beyaz, füme, gri, lacivert, kırmızı ve siyah' tır. Bu renkler artırılabilir. Fakat bilindiği üzere üç temel renk RGB değeri üzerinden diğer renkler türediği için bu çeşitliliği sağlamak problemin ihtiyacına göre değişiklik göstermektedir.

Python programlama dilinde RGB denk uzay1, BGR şeklinde tanımlanır. Burada Mavi(Blue(B)) kanal için 0, Yeşil(Green(G)) kanal için 1 ve Kırmızı(Red(R) kanalı için 2 indeks değeri olarak kullanılmaktadır. Elde edilen değerler döngüsü kullanılarak belirlenen aralıklardaki değerlere göre bir renk tespitinde bulunulmaktadır.

Örnek:

Aracin Rengi: Siyah

Ortalama BGR değeri: 724838

Sistem test aşamasında 20 adet görüntü üzerinde test edilmiş olup Tablo 1'de gösterilmektedir.

Tablo 1. Test Sonuçları

\begin{tabular}{|l|l|l|l|l|}
\hline \multirow{2}{*}{$\begin{array}{l}\text { Test } \\
\text { Sonuçları }\end{array}$} & \multicolumn{4}{|l}{ Test Özelliği } \\
\cline { 2 - 5 } & Renkler & DO ĞRU & YANLIŞ & Toplam \\
\hline \multirow{5}{*}{} & Beyaz & 5 & 0 & 5 \\
\cline { 2 - 5 } & Lacivert & 4 & 1 & 5 \\
\cline { 2 - 5 } & Kırmızı & 4 & 1 & 5 \\
\cline { 2 - 5 } & Siyah & 5 & 0 & 5 \\
\hline
\end{tabular}

Bu görüntülerdeki araca ait rengin yanlış tespit edilmesinin en temel nedeni görüntüdeki 1şı yansımaları sonucu oluşan piksel farklılıkları ya da gri ve füme renklerinin oldukça birbirlerine benzer olmasıdır. Örneğin füme rengine ait aracın görüntüsü üzerine düşen güneş 1şınlarının görüntüdeki aracın rengini daha açık ya da daha koyu hale dönüştürmesi sonucu meydana gelmektedir.

Oluşturulan açık kaynak kodlu yazılıma (Ağgül, 2020)' den ulaşılabilir.

\section{Sonuç}

Bu çalışmada, kamera görüntüleri kullanılarak araçların renk tespiti yapılmıştır. Önerilen yaklaşımda öncelikle aracın görüntüsü tam çerçeve şeklinde kamera yardımı ile elde edilir. Elde edilen görüntü üzerinde araca ait renk bilgisinin yoğun olduğu bölge kırpılarak renk tespitinde bulunulur. Önerilen yaklaşım istatistiki metotlara dayanan ve hızlı sonuç üretmektedir. Test aşamasında daha önce bilinen renklere sahip ve fotoğrafi alınan araçlar için \%90 oranında doğru renk tespiti gerçekleştirildiği görülmüştür.

$\mathrm{Bu}$ önerilen yaklaşımın dezavantajı ise bazı temel renkler üzerinde denendiğinde büyük bir sorun ile karşılaşılmıştır. Örneğin füme ile gri rengin birbiriyle karıştırılması veya bir siyah renkli araç görüntüsü üzerinde güneş 1 şığının sebep olduğu parlaklık sebebiyle görüntü üzerinde kırpılan bölgenin piksel renk değerlerinin değişmesine neden olmaktadır. Bu nedenle tespit edilen renkte hata oranı artmaktadır.

Fakat bu sorun renk tanıma üzerine incelenen tüm çalışmalarda, görülen bir sorun olarak belirlendiği görülmüştür. Hava koşulları vb. etkenlerden ötürü bazı renkler için doğru tespit yapılabilmesi için yüksek çözünürlüklü görseller kullanıldığında daha iyi sonuçlar elde edildiği de gözlemlenilmiştir. 
Kaynakça

Ağgül, B. (2020). Github/burakaggul. Github:

https://github.com/burakaggul/vehicle_color_recogn ition/blob/main/vehicle_color_recognition.py adresinden alınd 1

Brody Huval, T. W.-Y. (2015). An Empirical Evaluation of Deep Learning on Highway Driving., (s. 1-7).

Feng Wang, L. M. (2008). Fuzzy-based algorithm for color recognition of license plates. Pattern Recognition Letters, 1007-1020.

Huiyuan Fu, H. M. (2020). MCFF-CNN: Multiscale comprehensive feature fusion convolutional neural network for vehicle color recognition based on residual learning. Neurocomputing, 178-187.

Kwang-Ju Kim, P.-K. K.-T.-S.-J. (2018). Vehicle Color Recognition via Representative Color Region Extraction and Convolutional Neural Network. International Conference on Ubiquitous and Future Networks, ICUFN, (s. 89-94).

Mengjie Yang, G. H. (2011). Vehicle Color Recognition Using Monocular camera. 2011 International Conference on Wireless Communications and Signal Processing, WCSP 2011, (s. 0-4).

Q. Zhang, L. Z. (2018). Vehicle color recognition using Multiple-Layer Feature Representations of lightweight convolutional neural network. Signal Processing journal, 146-153.

Tiantian Wang, C. X. (2015). Vehicle recognition based on saliency detection and color histogram. Proceedings of the 2015 27th Chinese Control and Decision Conference, CCDC 2015, (s. 2532-2535).

Xiuzhi Li, G. Z. (2010). Vehicle color recognition using vector matching of template. 3rd International Symposium on Electronic Commerce and Security, ISECS 2010, (s. 189-193).

Yanmei Dong, M. P. (2015). Vehicle color recognition based on license plate color. Proceedings - 2014 10th International Conference on Computational Intelligence and Security, CIS 2014, (s. 264-267).

Yusuf Artan, B. A. (2019). Plaka Tanıma Kamera Görüntülerinde Derin Öğrenme. 22-25. 